\title{
Configuração da subjetividade lírica em As Enfibraturas do Ipiranga
}

\author{
SUBJECTIVITY IN AS ENFIBRATURAS DO IPIRANGA: MUSIC, \\ MASKS, SINCERITY AND TRADITION
}

Luana Uchôa Torres ${ }^{1}$

http://lattes.cnpq.br/6283497214395313

Enviado em: 02/11/2018

Aceito em: 21/12/2018

Canto da minha maneira. Que me importa si me não entendem? Não tenho forças bastantes para me universalizar? Paciência. Com o vário alaúde que construí, me parto por essa selva selvagem da cidade.

Mário de Andrade

\begin{abstract}
RESUMO: Este estudo discute sobre como se configura a subjetividade lírica em "As Enfibraturas do Ipiranga", poema que encerra o livro Pauliceia Desvairada (1922) do poeta Mário de Andrade. Entendemos que as características configuradas nesse poema, tais como a dubiedade de sujeito empírico e sujeito lírico; a ficcionalização do sujeito pelo uso de máscaras; a influência dos conhecimentos musicais e da erudição do poeta, e o diálogo com a tradição literária, resumem as características do livro como um todo. Nesse sentido, investigamos como o poeta utilizou-se desses aspectos na composição do poema em questão. Para o desenvolvimento da discussão, pautamonos, principalmente, nos estudos de Dominique Combe (2009/2010), Benedito Nunes (1984) e João Luiz Lafetá (2004).
\end{abstract}

PALAVRAS-CHAVE: Subjetividade Lírica, Pauliceia Desvairada, As Enfibraturas do Ipiranga, Mário de Andrade.

ABSTRACT: This study discusses how the lyrical subjectivity is configured in "As Enfibraturas do Ipiranga", a poem that ends the book Pauliceia Desvairada (1922) by the poet Mário de Andrade. We understand that the characteristics configured in this poem, such as the dubiety of the empirical subject and the lyrical subject; the fictionalization of the subject using masks; the influence of the poet's musical knowledge and erudition, and the dialogue with the literary tradition, sum up the characteristics of the book. In this sense, we investigate how the poet used these aspects in the composition of the poem in question. For the development of the discussion, we focus mainly on the studies of Dominique Combe (2009/2010), Benedito Nunes (1984) and João Luiz Lafetá (2004).

KEY-WORDS: Lyrical Subjectivity, Pauliceia Desvairada, As Enfibraturas do Ipiranga, Mário de Andrade.

O livro Pauliceia Desvairada (1922) marca a entrada do poeta Mário Raul de Morais Andrade (1893-1945) no modernismo. Nessa obra estão presentes temas variados, tais como, o urbano, progresso, cidade, arte, amor, política e música. Além disso, o poeta apresenta

\footnotetext{
${ }^{1}$ Doutoranda do programa de Pós-Graduação em Letras e Linguística da UFG, na área de Estudos Literários. Professora de Música do Instituto Federal de Goiás. Cantora lírica - soprano. E-mail: luana soprano@hotmail.com
} 
suas ideias modernistas e manifesta uma subjetividade questionadora, irônica e musical, prevalecendo o tom do deboche e combate. Desde o "Prefácio Interessantíssimo", percebemos que ele defende sua visão estética, a qual enxerga a poesia como um objeto artístico, como um artifício. Ou seja, demonstra preocupação com a linguagem e com o fator de fabricação e técnica no poema. Por outro lado, detectamos em seus poemas resquícios do eu pessoal do poeta. Nessa perspectiva, pretendemos demonstrar como, em "As Enfibraturas do Ipiranga", o poeta utilizou máscaras para disfarçar seu "eu", configurando um jogo entre fingimento e sinceridade. No que diz respeito a essa última, acreditamos que ela emerge pela marcação de território do sujeito empírico, especificamente ao que concerne à figura de Mário de Andrade como músico, erudito, sujeito complexo, que traz para os poemas seus conhecimentos musicais e sua memória de leitura da tradição literária.

Dominique Combe (2009/2010), em seu ensaio A referência desdobrada: o sujeito lírico entre a fição e a autobiografia, nos faz refletir sobre a ideia de não descartarmos o eu empírico do poeta ao analisarmos o sujeito lírico configurado em poemas. Entendemos, pois, que a constituição do sujeito lírico não está descolada do empírico, diferente do que postularam alguns teóricos alemães, tais como, Margarete Susman (1910). Contrariando esse caminho de anulação do sujeito empírico, Combe (2009/2010) afirma que a gênese do sujeito lírico é inseparável da relação entre literatura, biografia e referencialidade da obra. Em suas discussões, o autor esclarece que o sujeito lírico não é uma oposição ao sujeito empírico, pois, na verdade, ele precisa das experiências deste para se constituir.

Deste modo, o autor francês nos oferece outra solução para a questão, diferente de uma separação total desses sujeitos, entendendo que o sujeito lírico se constrói dentro de um movimento pendular, em um vaivém que, ora o sujeito tende para um lado, ora ele se encaminha para o outro. Isto é, ao invés de realizar oposição desses sujeitos, "o melhor seria abordar o problema de um ponto de vista dinâmico, como um processo, uma transformação ou, melhor ainda, um “jogo” (COMBE, 2009/2010, p.124). Nesse sentido, o lugar do sujeito lírico é, na verdade, um entre-lugar.

Esse movimento pendular provoca tensão e faz com que o sujeito seja dinâmico e performático, por isso instável. Por se construir dessa maneira, não podemos reduzi-lo a uma única identidade. Portanto, é um sujeito que não existe, mas se cria dentro do poema, sempre uma subjetividade em constante devir:

[...] Não há, a rigor, uma identidade do sujeito lírico. O sujeito lírico não poderia ser categorizado de uma forma estável, uma vez que ele consiste precisamente em um incessante duplo movimento do empírico em direção ao transcendental. Vale dizer então que o sujeito lírico, levado pelo dinamismo da ficcionalização, não está jamais acabado, e mesmo que ele não é. Longe de exprimir-se como um sujeito já constituído que o poema representaria ou exprimiria, o sujeito lírico está em permanente constituição, em uma gênese constantemente renovada pelo poema, fora do qual ele não existe. O sujeito lírico se cria no e pelo poema, que tem valor performativo. Essa gênese contínua impede, certamente, de definir uma identidade do sujeito lírico que se fundaria sobre uma relação do mesmo ao mesmo (COMBE, 2009/2010, p.128).

Por esse ângulo, sentimentos dispostos num poema são resultados da experiência vivida pelo poeta, no sentido de experiência humana. Combe prefere denominar isto de dupla referência ou referência desdobrada, por meio da qual o sujeito se volta para si e para o mundo, possuindo, portanto, dupla intencionalidade. O que ocorre, para ainda utilizar as terminologias de Combe, é um disfarce lírico, um autofigurar-se, ou uma autoalegorização. 
Essa alegoria acontece num movimento que, metonimicamente, vai do particular para o geral, ou seja, uma redescrição lírica, pela qual o sujeito empírico é ampliado. Logo, o sujeito empírico é ultrapassado pelo lírico, que o universaliza. "O eu lírico amplia o singular até a potência do geral ou até o universal. [...] o "eu" em poesia, como em todo texto literário, não é ‘verdadeiro' nem ‘falso' na representação do poeta (COMBE, 2009/2010, p. 123).

Com efeito, dentro dessa perspectiva, longe de uma polarização na expressão do eu do poeta, ocorre uma interação entre sujeito empírico e sujeito lírico. Ou seja, o sujeito de quem falamos está longe de ser a representação do sujeito real-poeta, é muito mais o resultado da mediação entre esses dois sujeitos. Contudo, embora eles se encontrem, não se confundem um com o outro, e essa mediação não resulta em uma forma bem delineada. $\mathrm{Na}$ verdade, ela se configura de diferentes modos, dependendo do que o texto, ou melhor, a voz lírica expressa.

Combe, portanto, nos lembra da ideia de uma redescrição retórica do sujeito empírico pelo sujeito lírico. Nesse sentido a máscara que o sujeito lírico assume é um écart figural (um intervalo figural) em relação ao sujeito autobiográfico. Nessa distância criada, o sujeito assume um valor de "ele", tornando-se o seu próprio objeto. Desse modo, a construção desse sujeito lírico é mais como uma recriação, sendo o resultado da manifestação de várias máscaras que se criam dentro do organismo do poema. Portanto, o sujeito lírico aparece como um sujeito autobiográfico ficcionalizado; ou o inverso, o sujeito fictício se inscreve na realidade do empírico segundo um movimento pendular. Tal movimento enxergamos em "As Enfibraturas do Ipiranga”, quando, por exemplo, a voz Minha Loucura se apresenta como uma alegoria do eu do poeta.

O que ocorre em Pauliceia Desvairada é que o sujeito usa uma máscara poliédrica, com várias faces, ou, para utilizarmos um termo mais apropriado, é uma máscara com vários losangos. De acordo com João Luiz Lafetá (2004),

De fato, a subjetividade está ali submetida a grande pressão que estoura tudo - o eu, a cidade, a linguagem -, tudo submetendo à fragmentação. Como no caso das pulsões analisadas por Freud, nunca se pode apreender diretamente o sujeito lírico, que desliza de metamorfose em metamorfose, ora numa, ora noutra forma. Suas vicissitudes deixam marcas na linguagem dos poemas, cicatrizes que testemunham a complexidade das forças liberadoras forças liberadoras e repressivas em jogo (LAFETÁ, 2004, p. 358-359).

Entendemos que a experiência de vida de Mário de Andrade se instala nos poemas da Pauliceia. Quanto a isso, destacamos sua relação com a música, uma vez que ele estudou música no Conservatório Dramático e Musical de São Paulo, foi musicólogo, professor de piano, crítico musical, pioneiro da Etnomusicologia, e escreveu diversos livros sobre música. A arte musical parece influenciar na sua maneira de escrever. Aliás, é recorrente o fato de ele utilizar a música em toda sua obra, seja como tema, forma ou conteúdo. Inclusive, ele teorizou sobre o fazer poético pela música, e parte dessas reflexões se encontram no próprio "Prefácio Interessantíssimo" da Pauliceia. Em relação a esse ponto, é interessante assinalarmos que ele foi nomeado para Cátedra de História da Música no Conservatório Dramático e Musical de São Paulo em janeiro de 1922, mesma época de publicação do seu livro marco do modernismo.

Dentre suas correspondências com Manuel Bandeira, há uma carta de outubro de 1922, na qual Mário de Andrade comenta sobre a presença da música na Pauliceia: 
Creio que tens razão quanto à excessiva musicalidade dos meus versos. Caí muitas vezes num domínio inteiramente musical. Agora: o leitor está avisado que meus versos devem ser ditos. Ainda continuo neste pensar: versos são para se dizer. O poeta é sempre um rapsodo. Em todo caso procuro agora tirar dos meus versos essa musicalidade demasiado objetiva, visando conservar a arte da palavra dentro dos meios que lhe são próprios; clareza, sonoridade falada, sentido de dicionário etc. (MORAES, 2001, p. 72).

De acordo com Benedito Nunes (1984), referindo-se ao livro Pauliceia:

Difícil é classificar a personalidade artística desse poeta, narrador, crítico e ensaísta, que criou, com a argúcia paciente de um pesquisador, e que pesquisou a realidade brasileira com o ímpeto luminoso de um criador. Terá sido ele o nosso primeiro scholar, surgido antes das Universidades - um singular scholar autodidata, oposto ao diletantismo -. Enquanto os seus companheiros de geração vinham, na grande maioria, das Faculdades de Direito, Mário de Andrade tinha, como título de estudos superiores, um curso de piano no Conservatório de São Paulo, que lhe deu a inusitada condição, aquela época, de musicólogo, avis rara entre bacharéis de arribação em Letras Jurídicas. A esse poeta, que assinou ensaios capitais sobre música brasileira, e lançou os fundamentos de nossa historiografia artística - a esse musicólogo, inseparável do poeta, devese a poesia matricial do modernismo (NUNES, 1984, p. 64).

No poema "As Enfibraturas do Ipiranga" são evidenciados os conhecimentos que o poeta tem acerca da tradição musical e da tradição literária. Esse poema encerra o livro Pauliceia Desvairada e recebe a denominação de Oratório Profano. Nele, Mário de Andrade estrutura um libreto para um oratório, identificando as divisões de vozes, formação orquestral e coral a serem utilizadas. Nunes (1984, p. 69), nos lembra que o título se refere ao riacho do Ipiranga, da proclamação que D. Pedro I fez. Portanto, trata-se de uma ironia à comemoração do centenário da Proclamação da Independência do Brasil. Porém, podemos também enxergar uma alegoria do acontecimento da Semana de Arte Moderna, do combate entre passadistas e modernos.

A representação da Semana de Arte Moderna como confronto estético entre passadistas e modernistas é apenas o primeiro plano de As Enfibraturas do Ipiranga. O plano de fundo, onde o sentido da composição se projeta, para além de seu significado mais óbvio, passa pela posição dramática das massas corais, representativas, dentro do espaço cênico, de grupos socialmente definidos, cada um dos quais correspondendo a certo modo de atuação, de pensamento e de sensibilidade. O confronto artístico transfigura-se num estarrecido confronto social. Desdobram-se as fibras estéticas do modernismo em filamentos, em fibraturas ideológicas (NUNES, 1984, p. 73-74).

O poema é composto por diversas vozes que encenam o caos da São Paulo dos anos 1920, a qual vivia processo de industrialização. Cada grupo com sua identidade e ideologias se dividem em: os Orientalismos Convencionais - escritores e outros artistas submetidos ao passado, que no cenário estão colocados nas janelas do teatro Municipal; as Senectudes Tremulinas - milionários e burgueses que estão em locais frequentados pela alta sociedade, tais como o Automóvel Clube, Rotisserie e Hotel Carlton; os Sandapilários Indiferentes operariado, posicionados no viaduto do Chá; as Juvenilidades Auriverdes - os artistas modernistas, rebeldes que lutam pela mudança no Brasil, localizados no vale do Anhangabaú; e a Minha Loucura - alegoria do próprio poeta, posicionada junto às Juvenilidades. Nesse sentido, observamos que o poeta configurou diferentes estruturações e formas para simbolizar as vozes às quais ele se refere. Cada máscara é um losango, temos, portanto, os vários losangos, da roupa do arlequim, formando múltiplas cores, cada um assumindo sua 
identidade e defendendo seu espaço.

Verificamos alguns pontos de relação com a música, como, por exemplo, a própria escolha pelo gênero oratório. Além disso, a divisão das vozes não é arbitrária. Os Orientalismos são constituídos por um coro a quatro vozes (sopranos, contraltos, barítonos e baixos) afinadíssimo. Eles são os que preferem música tradicional europeia e defendem a metrificação dos versos. As Senectudes são um coro de sopranistas, com vozes trêmulas, como o próprio nome sugere, caracterizados nos poemas pelas músicas e danças barrocas de corte, como o minuete e a gavota. No trecho seguinte, podemos observar, a estruturação do poema que segue o ritmo ternário do minuete:

\section{AS SENECTUDES TREMULINAS \\ (tempo de minuete)}

Quem são estes homens?

Maiores menores

Como é bom ser rico!

Maiores menores

Das nossas poltronas

Maiores menores.

Olhamos as estátuas

Maiores menores

Do signor Ximenes

- O grande escultor!

Só admiramos os célebres

E os recomendados também!

Quem tem galeria

Terá um Bouguereau!

Assinar o Lírico?

Elegância de preceito!

Mas que paulificância

Maiores menores

O Tristão e Isolda!

Maiores menores

Preferimos os coros

Dos Orientalis -

mos Convencionais!

Depois os sanchismos

(Ai! gentes, que bom!)

Da alta madrugada

No largo do Paiçandu!

Alargar as ruas...

$\mathrm{E}$ as Instituições?

Não pode! Não pode!

Maiores menores

Mas não há quem diga

Maiores menores

Quem são estes homens

Que cantam do chão?

(a orquestra súbito emudece, depois duma 
As Juvenilidades são constituídas por tenores, associados aos herois; e a Minha

Loucura é uma solista, com voz de soprano ligeiro, acompanhada pela configuração instrumental de harpa e trompa. Salientamos a associação com um soprano ligeiro, uma vez que na tradição de classificações vocais operísticas esse tipo de voz muitas vezes é relacionado às personagens loucas. Além disso, não poderíamos deixar de observar que essa voz pode ser entendida como a voz do próprio poeta. Mário de Andrade insere ele mesmo no poema ou, pelo menos, fundamentando-nos pelas reflexões de Combe, dizemos que ele elabora uma autoalegoria.

Essa voz aparece em meio à multidão, embora não se dissolva nela, caracterizando-se mais como um corenta, ou uma voz monódica que rege o coro. Apresenta-se como um contracanto, que vai na contramão de todas as outras vozes, pois caminha sozinha - solista - afirmando-se como o diferente, individualizada. Contudo, ao mesmo tempo ela é reflexo do caótico. Entretanto, por mais que seja destoante da sociedade, é um canto melodioso. Essa é a voz que rompe a algazarra para cantar esperançosa, como evidenciam os versos "As rosas... as borboletas... os orvalhos". Tais vocábulos demonstram um conjunto simbólico para regeneração, caracterizando o renascer da cidade e de suas vozes.

\section{MINHA LOUCURA}

(suavemente entoa a cantiga de adormentar)

Chorai! Chorai! Depois dormi!

Venham os descansos veludosos

Vestir os vossos membros!... Descansai!

Ponde os lábios na terra! Ponde os olhos na terra!

Vossos beijos finais, vossas lágrimas primeiras

Para a branca fecundação!

Espalhai vossas almas sobre o verde!

Guardai nos mantos de sombra dos manacás

Os vossos vaga-lumes interiores!

Inda serão um Sol nos oiros do amanhã!

Chorai! Chorai! Depois dormi!

A mansa noite com seus dedos estelares

Fechará nossas pálpebras...

As vésperas do azul!...

As milhores vozes para vosso adormentar!

Mas o Cruzeiro do Sul e a saudade dos martírios...

Ondular do vaivém! Embalar do vaivém!

Para a restauração o vinho dos noturnos!...

Mas em vinte anos se abrirão as searas!

Virão os setembros das floradas virginais!

Virão os dezembros do Sol pojando os grânulos!

Virão os fevereiros dos café-cereja!

Virão os marços das maturações!

Virão os abris dos preparativos festivais!

E nos vinte anos se abrirão as searas!

E virão os maios! E virão os maios! 
Rezas de Maria... Bimbalhadas... Os votivos...

As preces subidas... As graças vertidas...

Tereis a cultura da recordação!

Que o Cruzeiro do Sul e a saudade dos martírios

Plantem-se na tumba da noite em que sonhais...

Importa?!... Digo-vos eu nos mansos

Oh! Juvenilidades Auriverdes, meus irmãos:

Chorai! Chorai! Depois dormi!

Venham os descansos veludosos

Vestir os vossos membros!... Descansai!

Diuturnamente cantareis e tombareis.

As rosas... As borboletas... Os orvalhos...

O todo-dia dos imolados sem razão...

Fechai vossos peitos!

Que a noite venha depor seus cabelos aléns

Nas feridas de ardor dos cutilados!

E enfim no luto em luz, (Chorai!)

Das praias sem borrascas, (Chorai!)

Das florestas sem traições de guaranis

(Depois dormi!)

Que vos sepulte a Paz Invulnerável!

Venham os descansos veludosos

Vestir os vossos membros... Descansai!

(quase a sorrir, dormindo)

Eu... os desertos... os Cains... a maldição. . .

(ANDRADE, 2016, p. 91-93).

Baseando-nos pela simbologia da figura do arlequim, consideramos que o sujeito lírico apenas adentra à Pauliceia se vestir a máscara da loucura. Pois, de acordo com Jean Chevalier e Alain Gheerbrant (2000), arlequim é

Nome que vem da antiga comédia italiana ("commedia dell'Arte", cujo objetivo original era o de divertir o público ridicularizando os costumes, esquisitices e extravagâncias da sociedade burguesa da época [séc. XVI]). Denominava um personagem classicamente trajado com uma roupa feita de pedaços de pano triangulares e de cores diferentes; usava uma máscara negra a esconder-lhe os olhos e um sabre de madeira à cintura. Encarnava os papeis de jovem gaiato, de bufão malicioso, de um indivíduo matreiro embora meio pateta, e de leviano. Sua vestimenta multicor sublinhava sobretudo esse último aspecto. $\mathrm{O}$ arlequim é a imagem do irresoluto e do incoerente, que não se prende a ideias, sem princípios e sem caráter. Seu sabre é apenas de madeira, seu rosto anda sempre mascarado, sua vestimenta é feita de remendos, de pedaços de pano. A disposição desses pedaços em xadrez evoca uma situação conflitiva - a de um ser que não conseguiu individualizar-se, personalizar-se e desvincular-se da confusão dos desejos, projetos e possibilidades (CHEVALIER e GUEERBRANT, 2000, p. 80).

A epígrafe do poema "As Enfibraturas do Ipiranga" nos oferece uma chave de interpretação, pois trata-se de um trecho do solilóquio da personagem Ofélia no ato III, cena I, da tragédia Hamlet de William Shakespeare, quando ela, aturdida por ter visto e conversado com Hamlet, pergunta-se como ele pôde se tornar aquele ser transtornado. Perplexa e decepcionada, Ofélia lamenta o quanto ela é miserável por ter visto um Hamlet de mente tão 
nobre e agora está vendo-o tão louco e atordoado: "O, woe is me/ To have seen what I have seen, see what I see" - ("E eu, pobre miserável,/ Tendo visto o que vi, ver o que vejo" SHAKESPEARE, 2010, p. 122).

Esse aspecto demonstra a erudição de Mário de Andrade e o diálogo que ele realiza com a tradição literária. Podemos também fazer um paralelo entre a fala de Ofélia e a voz lírica expressa em "As Enfibraturas do Ipiranga". Tal voz está perplexa com a transformação da Pauliceia e/ou com a sua própria mudança. Lembramos também que, na tragédia inglesa, as personagens pensam que Hamlet está louco, mas na verdade ele é mais sábio do que louco, pois tem consciência do que se passa. Isso é semelhante ao que ocorre no poema de Mário de Andrade. Além disso, ambos tratam da escória, de uma corja social. O primeiro sobre o do Reino da Dinamarca, e a segunda da burguesia da Pauliceia. Assim como Hamlet, o sujeito de As Enfibraturas é quem vê o problema, enquanto os outros não enxergam ou não querem enxergar. A crise de Hamlet é dele e de toda Dinamarca, do mesmo modo é em As Enfibraturas: a crise do sujeito lírico é dele e de toda a Pauliceia. Portanto, é uma subjetividade em crise. A voz lírica está perplexa diante da Pauliceia, mas por outro lado se refere ao seu próprio desvario.

De fato, prevalece o conflito entre o sujeito empírico - sinceridade - e sujeito lírico máscaras. Ele dissimula, mas também mantém vestígios de seu eu pessoal. Esses vestígios aparecem evidenciados nos conhecimentos musicais e da tradição literária que emergem nos poemas. A escolha pela máscara é para o fingimento. Assim, do mesmo modo como as pessoas aproveitam o momento do carnaval para expor lados obscuros que, no dia a dia, não podem expor, devido às regras da sociedade, o poeta veste a máscara da loucura. No entanto, ela parece ter rachaduras, pelas quais se infiltra o eu pessoal do poeta. O sujeito lírico de As Enfibraturas se reconhece em meio aos losangos, como parte do todo, embora mantenha sua individualidade. Ou seja, ele não se dissolve na multidão. Em alguns momentos o disfarce é descoberto. Por isso dizemos que nesse poema o "eu" se apresenta ora mascarado, ora desvelado.

Nesse sentido, em "As Enfibraturas do Ipiranga" há um jogo entre polifonia versus subjetividade. Embora utilize a máscara para dissimular o seu "eu", a sinceridade, o traço do eu do poeta, insiste em restar, aparecendo de maneira evidente nas partes musicais e na defesa dos ideais modernistas. A subjetividade em toda Pauliceia se mostra pendular, oscilando entre o empírico e o lírico. Esse sujeito em crise, que se utiliza de máscaras para expressar as vozes de São Paulo, também se coloca como um dos losangos no meio do caos da Pauliceia. Tal jogo é evidenciado em As Enfibraturas, com a presença do sujeito músico e erudito do poeta, conectado à tradição musical e literária, e à situação social, política e artística do Brasil dos anos 20. Em suma, o que ocorre é um jogo entre máscaras (que são faces de uma mesma) e a sinceridade do poeta.

\section{REFERÊNCIAS}

ANDRADE, Mário de. Pauliceia Desvairada. In: De Pauliceia Desvairada a Lira

Paulistana. São Paulo: Martin Claret, 2016.

CHEVALIER, Jean \& GHEERBRANT, Alain. Dicionário de símbolos: mitos, sonhos, costumes, gestos, formas, figuras, cores, números. Tradução de Vera da Costa e Silva et al. 15. ed. Rio de Janeiro: José Olympio, 2000. 
COMBE, Dominique. A referência desdobrada; o sujeito lírico entre a ficção e a autobiografia. Tradução de Iside Mesquita e Vagner Camilo. Revista USP, São Paulo, n.84, p. 112-128, dezembro/fevereiro, 2009-2010.

LAFETÁ, João Luiz. A representação do sujeito lírico na Pauliceia desvairada. In: PRADO, Antonio Arnoni (Org.). A dimensão da noite e outros ensaios. São Paulo: Duas Cidades; Editora 34, 2004.

MORAES, Marcos Antonio de. (Org.). Correspondência Mário de Andrade e Manuel Bandeira. São Paulo: Editora da Universidade de São Paulo: Instituto de Estudos Brasileiros, Universidade de São Paulo, 2001.

NUNES, Benedito. Mário de Andrade: as enfibraturas do modernismo. In: Revista Ibero Americana. vol. L, n. 126, p. 63-75, janeiro/março 1984.

SHAKESPEARE, William. Hamlet, Rei Lear, Macbeth. Tradução de Barbara Heliodora. São Paulo: Abril, 2010. 